\title{
(C) OPEN ACCESS \\ Long-term control of laryngeal plasma cell mucositis with systemic immunosuppression
}

\author{
James Triplett, ${ }^{1}$ Geoffrey Hee, ${ }^{2}$ Andrew McLean-Tooke, ${ }^{1}$ Michaela Lucas ${ }^{1,3,4}$
}

'Department of Immunology, Sir Charles Gairdner Hospital, Perth, Western Australia, Australia ${ }^{2}$ Department of Otolaryngology, Sir Charles Gairdner Hospital, Perth, Western Australia, Australia

${ }^{3}$ Faculty of Medicine, University of Western Australia, Australia ${ }^{4}$ Institute for Immunology and Infectious Diseases, Murdoch University, Perth, Western Australia, Australia

Correspondence to

Dr James Triplett, james.triplett@health.wa.gov. $\mathrm{au}$

teddytriplett@hotmail.com

Accepted 25 May 2018

Check for updates

(c) BMJ Publishing Group Limited 2018. Re-use permitted under CC BY-NC. No commercial re-use. See rights and permissions. Published by BMJ.

\section{To cite: Triplett J,}

Hee G, McLean-Tooke A,

et al. BMJ Case Rep

2018:2018:e221333.

doi:10.1136/bcr-2017-

221333

\section{SUMMARY}

Plasma cell mucositis (PCM) is a rare non-neoplastic plasma cell proliferative disorder of the mucous membranes, which typically presents as soft tissue lesions involving oral, upper airway or genital mucosa. Laryngeal involvement resulting in stridor has been reported in four other cases previously, with three requiring tracheostomy. We present a case of supraglottic stenosis in a 53-year-old woman presenting with dysphonia and stridor, requiring surgical resection on three occasions accompanied by tracheostomy on two occasions; biopsy was consistent with PCM. Due to relapsing disease activity, high-dose prednisolone and mycophenolate mofetil were commenced with prednisolone eventually being ceased. After 2 years of mycophenolate mofetil therapy, the patient's disease has been controlled without need for further surgical intervention. This is the first reported case of prolonged symptomatic improvement with the use of systemic immunosuppressive therapy with mycophenolate mofetil in PCM.

\section{BACKGROUND}

Plasma cell mucositis (PCM) is a non-neoplastic plasma cell proliferative disorder of the mucous membranes that typically presents as soft tissue lesions. We report the first case of prolonged symptomatic improvement and prevention of relapse with systemic immunosuppression in a 53-year-old woman with supraglottic stenosis who after her third surgical resection has received 2 years of mycophenolate mofetil and prednisolone.

PCM is a benign condition of unknown aetiology characterised by infiltration of plasma cells of the mucous membranes which may affect oral, upper airway or genital mucosa. PCM is more common in men (1.2:1) with onset typically after the fourth decade. ${ }^{1}$ The natural history of PCM is not fully understood though a case of PCM transitioning to squamous cell carcinoma has been reported. ${ }^{2}$ The oral cavity and oropharynx are commonly affected while the larynx and genitals are occasionally affected. Laryngeal lesions are described as having a cobblestone appearance and present with symptoms of stridor, dyspnoea or dysphonia.

Common presenting symptoms of PCM include gradual onset of chronic oral and throat pain, dysphagia and dysphonia. The chronic nature of symptoms differentiates PCM from post radiation mucositis, which generally presents with pain, odynophagia and dysphagia 10-14 days after the onset of radiation therapy. ${ }^{34}$ The clinical differential diagnosis of PCM includes infections, sarcoidosis, erosive lichen planus, squamous cell carcinoma, allergic gingivostomatitis, granulomatosis with polyangitis, rhinoscleroma, mucous membrane pemphigoid and pemphigus. To differentiate PCM from these other disorders, a biopsy is typically required. The majority of previously reported cases of PCM required multiple investigations and biopsies prior to the correct diagnosis being made.

Characteristic PCM lesions are described histologically as having an acanthotic epithelium with narrow and elongated rete ridges, spongiosis and a dense subepithelial infiltrate mainly composed of mature plasma cells without anaplasia or prominent nucleoli. Russell bodies are occasionally seen. Immunoperoxidase staining typically shows a lack of $\mathrm{K}$ or L light-chain restriction and various heavy chains. The histological differential diagnosis for PCM includes conditions associated with dense, submucosal mature plasma cell infiltrates, such as extramedullary plasmacytoma, and plasma cell gingivitis and less commonly reactive plasmacytic hyperplasia, plasma cell granuloma, plamacytoid lymphoma, plasmacanthoma and POEMS (polyneuropathy, organomegaly, gammopathy and skin changes) syndrome.

There are 13 previous cases of laryngeal PCM with 4 resulting in stridor, of which 3 required tracheostomy, with the fourth having a benign course without relapse that responded to treatment with surgical debulking, topical therapies and systemic steroids. ${ }^{5-7}$ PCM has previously been treated with local and systemic prednisolone, surgical therapy and radiotherapy but not other forms of immunosuppression. Progression of PCM to a plasma cell neoplasm or lymphoma has never been reported, though progression to squamous cell carcinoma has been recently reported. ${ }^{2}$

\section{CASE PRESENTATION}

A 53-year-old woman presenting with dysphonia and dyspnoea was investigated with CT of the neck and laryngoscopy. She was found to have mild laryngeal stenosis and commenced on a proton pump inhibitor for presumed laryngopharyngeal reflux. Fifteen months later, she represented with worsening dyspnoea and stridor at this time CT imaging showed severe laryngeal stenosis (figure 1). The patient underwent laser resection and tracheostomy, though no biopsy was performed. She was weaned from tracheostomy without any initial complications. 


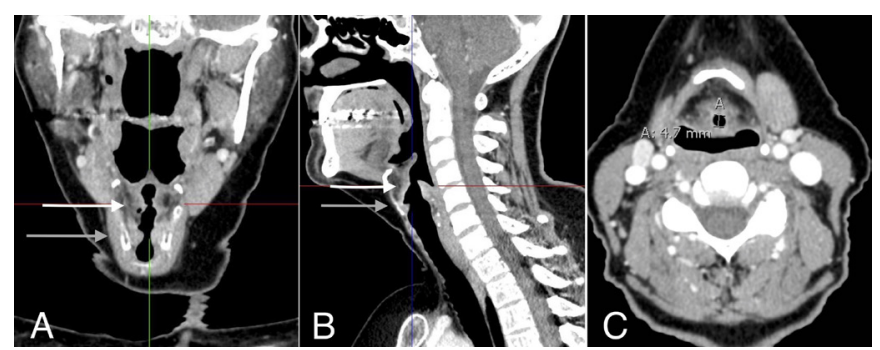

Figure 1 (A) Coronal CT scans showing supraglottic stenosis, identified by a white arrow, the glottic level (vocal cords) is identified by a grey arrow. (B) Sagittal CT scans showing supraglottic stenosis, identified by a white arrow, the glottic level (vocal cords) is identified by a grey arrow. (C)Axial CT scan identifying a maximal laryngeal diameter of $4.7 \mathrm{~mm}$ at the level of supraglottic stenosis.

Six months after the tracheostomy being performed, the patient had further laser surgery due to recurrence of symptoms, again presenting with dysphonia and stridor. Three months later, the patient again presented with stridor imaging and laryngoscopy revealed recurrent stenosis of the supraglottic larynx and a laryngeal diameter of $5 \mathrm{~mm}$. The glottic and subglottic airways however were normal in diameter and appearance (figure 2). Due to severity of the stridor and respiratory compromise, the patient underwent emergency tracheostomy and resection and biopsy followed by prednisolone $50 \mathrm{mg}$ daily.

The laryngeal biopsy findings were consistent with PCM. Biopsied tissue showed a highly abnormal polyclonal plasmacytic infiltrate within the subepithelial tissue, elongated rete ridges, spongiosis, epithelial inflammation and associated scarring. The subepithelial infiltrates mainly composed of mature plasma cells characterised by eccentric nuclei and abundant cytoplasm and were arranged in a sheet-like pattern. No fungi or spirochete organisms were identified and no viral inclusions were seen. There was no histological evidence of vasculitis and no granulomatous inflammation. Immunohistochemical staining showed cells to be a mixture of CD3-positive T cells and CD20-positive $\mathrm{B}$ cells with significant numbers of CD138-positive polyclonal plasma cells. Immunoperoxidase staining revealed a mixture of kappa-positive and lambda-positive (polyclonal) plasma cells. There was no immunoglobulin (Ig)G4 dominance to suggest IgG4 disease (figure 3).

Four weeks later, a repeat laryngoscopy was performed which identified a degree of ongoing suprgalottic stenosis, so a further surgical resection of the supraglottic stenotic lesion was performed. The biopsy tissue at this time showed marked

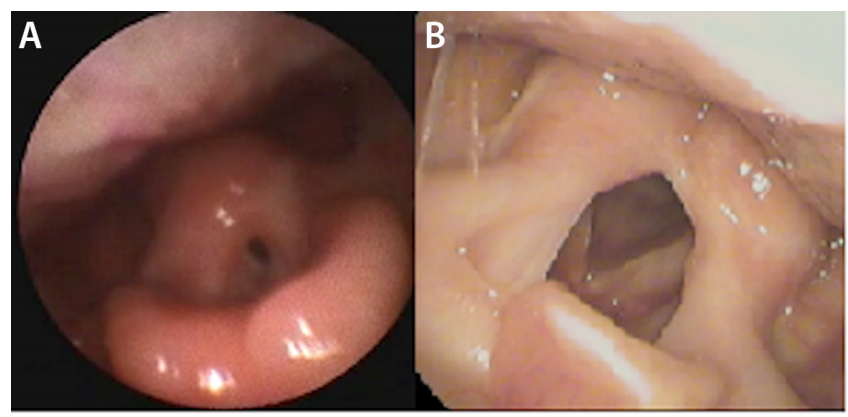

Figure 2 (A) Laryngoscopic image revealing supraglottic stenosis and reduced laryngeal diameter. (B) Larynoscopic image revealing a truncated epiglottis, scarred art-epilgottic folds and normal subglottis.

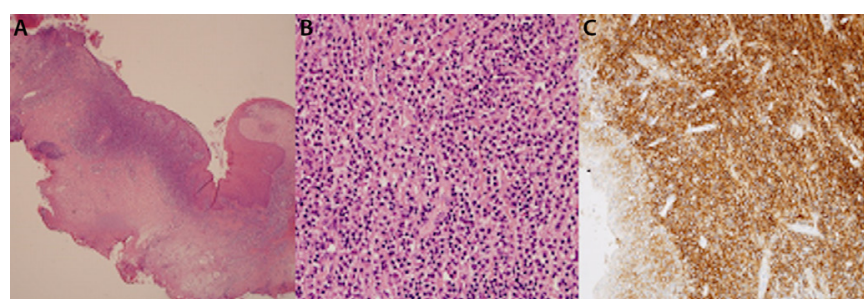

Figure 3 (A) Hyperplastic squamous epithelium overlying a dense lymphoplasmacytic subepithelial infiltrate. (B) Dense subepithelial infiltrate of mature plasma cells with eccentric nuclei and abundant cytoplasm. (C) Positive immunostaining for CD138 confirms the presence of numerous plasma cells.

fibrosis with reduced plasma cell burden compared with the previous biopsy.

Other laboratory investigations at the time revealed a positive atypical antineutrophil cytoplasmic antibody with negative myeloperoxidase and proteinase 3 antibodies, a speckled antinuclear antibody of 1:1280 with a negative extractable nuclear antigen. Smooth muscle antibodies (F-actin antibodies), were weakly positive with a arterial vessel, glomeruli and peritubular (VGT) staining pattern seen, though were accompanied by normal liver function tests and imaging. Full blood count, renal function, erythrocyte sedimentation rate, C3 and C4, immunoglobulins, IgG subclasses and serum-free light chain ratio were all within the normal range. There was no para-protein identified on serum and urine electrophoresis and no monoclonal population of aberrant B cells was identified on flow-cytometric immunophenotyping.

\section{OUTCOME AND FOLLOW-UP}

After removal of the tracheostomy, the patient was maintained on prednisolone $50 \mathrm{mg}$ for 2 weeks and then a steroid sparing agent was added. Azathioprine was commenced though the patient developed an adverse drug reaction at a dose of $75 \mathrm{mg}$ daily when she developed a maculopapular rash and hepatitis. She was therefore transitioned to mycophenolate mofetil (gradually increased to $1.5 \mathrm{~g}$ two times per day), which she remains on. Prednisolone was slowly tapered to none over 12 months. There has been no evidence of recurrence for 24 months and no disease progression on 3 monthly laryngoscopies.

\section{DISCUSSION}

The most effective treatment for PCM is debated, with both surgical and pharmacological approaches having been previously utilised. Short-term corticosteroid use in laryngeal disease has previously resulted in initial improvement of symptoms though is eventually followed by disease progression despite ongoing use. $^{2}$ To our knowledge, there are no other cases described in the current literature that utilises long-term systemic immunosuppression in the form of mycophenolate mofetil for relapsing laryngeal PCM.

Larger lesions causing obstructive symptoms may require debulking with laser or surgical resection. ${ }^{2}$ Short-lived response to balloon angioplasty dilatation has also been reported. ${ }^{8}$ Historically, patients who underwent surgical resection for laryngeal disease had temporary benefit followed by relapse, with more severe cases requiring tracheostomy. ${ }^{5-7}$

There are no reported cases of PCM being treated with systemic immunosuppressive agents other than corticosteroids. Given the abnormal polyclonal plasma cell population seen in PCM, pharmacological therapies that inhibit B-cell proliferation 
Learning points

- Plasma cell mucositis (PCM) is a benign condition of unknown aetiology characterised by infiltration of plasma cells of the mucous membranes, which may affect oral, upper airway or genital mucosa.

- Laryngeal lesions are described as having a cobblestone appearance and present with symptoms of stridor, dyspnoea or dysphonia.

- The most effective treatment for PCM is debated, with both surgical and pharmacological approaches having been previously utilised.

- This is the first case of sustained disease control due to the use of systemic immunosuppressive therapy with mycophenolate mofetil in PCM.

could be considered as potential treatment options, these include azathioprine, mycophenolate mofetil or sodium and the antiCD20 monoclonal antibody rituximab. Mycophenolate acts by inhibiting the inosine monophosphate dehydrogenase and thus decreasing de novo synthesis of guanosine nucleotides, which B lymphocytes are dependent on.

This is the first case of sustained disease control due to the use of systemic immunosuppressive therapy with mycophenolate mofetil in PCM. Given the risk of long-term side effects of mycophenolate, including gastrointestinal haemorrhage, increased infection and malignancy risk, this type of treatment should be reserved for relapsing and life-threatening disease.

Acknowledgements The authors would like to acknowledge Dr Nathan Harvey from the department of AnatomicalPathology, PathWest, Laboratory Medicine, QE II Medical Centre, Perth,Australia for providing histopathological specimens.

Contributors JT: responsible for identification of case, manuscript authorship and literature review. GH: responsible for identification of case and manuscript review. AM-T: responsible for manuscript review. ML: responsible for case identification, manuscript authorship and manuscript review. No financial support or funding was involved in the publication of this paper.
Funding The authors have not declared a specific grant for this research from any funding agency in the public, commercial or not-for-profit sectors.

Competing interests None declared.

Patient consent Obtained.

Provenance and peer review Not commissioned; externally peer reviewed.

Author note Immunotherapy-induced remission of laryngeal Plasma Cell Mucositis James Triplett1, Geoffrey Hee2, Andrew McLean-Tooke1, Michaela Lucas1, 3,4,5

1 Department of Immunology, PathWest, Laboratory Medicine, QE II Medical Centre, Perth, Australia.

2 Department of Surgery, Sir Charles Gairdner Hopsital, Perth, Australia Medicine, QE II Medical Centre, Perth, Australia.

3 School of Medicine and Pharmacology, University of Western Australia, Australia. 4 School of Pathology and Laboratory Medicine, University of Western Australia, Australia. 5 Institute for Immunology and Infectious Diseases, Murdoch University, Australia.

Open access This is an open access article distributed in accordance with the Creative Commons Attribution Non Commercial (CC BY-NC 4.0) license, which permits others to distribute, remix, adapt, build upon this work non-commercially, and license their derivative works on different terms, provided the original work is properly cited and the use is non-commercial. See: http://creativecommons.org/ licenses/by-nc/4.0/

\section{REFERENCES}

1 Solomon LW, Wein RO, Rosenwald I, et al. Plasma cell mucositis of the oral cavity: report of a case and review of the literature. Oral Surg Oral Med Oral Pathol Oral Radiol Endod 2008; 106:853-60.

2 Pepper T, Shekar K, Singh M, et al. Squamous cell carcinoma arising in mucosal plasmacytosis. Br J Oral Maxillofac Surg 2010;48:208-10.

3 Bonomi M, Camille N, Misiukiewicz K, et al. Assessment and management of mucositis in head and neck cancer patients. Clin Investig 2012;2:1231-40.

4 Trotti A, Bellm LA, Epstein JB, et al. Mucositis incidence, severity and associated outcomes in patients with head and neck cancer receiving radiotherapy with or without chemotherapy: a systematic literature review. Radiother Oncol 2003;66:253-62.

5 Ferriero JA, Rgorshin $\mathrm{EV}$, Olsen $\mathrm{KD}$, et al. Mucous 3 -membrane plasmacytosis of the upper aerodigestive tract. A clinicopathologic study. Am J Surg Pathol 1994:18:1048-53.

6 Timms MS, Sloan P. Association of supraglottic and gingival idiopathic plasmacytosis. Oral Surg Oral Med Oral Pathol 1991;71:451-3.

7 Fogarty G, Turner H, Corry J. Plasma cell infiltration of the upper aerodigestive tract treated with radiation therapy. J Laryngol Otol 2001;115:928-30.

8 Mistry SG, Watson GJ, Rothera MP. Balloon dilatation to treat plasmacytosis of the supraglottic larynx. J Laryngol Otol 2012;126:1077-80.

Copyright 2019 BMJ Publishing Group. All rights reserved. For permission to reuse any of this content visit

https://www.bmj.com/company/products-services/rights-and-licensing/permissions/

BMJ Case Report Fellows may re-use this article for personal use and teaching without any further permission.

Become a Fellow of BMJ Case Reports today and you can:

- Submit as many cases as you like

- Enjoy fast sympathetic peer review and rapid publication of accepted articles

- Access all the published articles

- Re-use any of the published material for personal use and teaching without further permission

For information on Institutional Fellowships contact consortiasales@bmjgroup.com

Visit casereports.bmj.com for more articles like this and to become a Fellow 